\title{
Abundant Nucleostemin Expression Supports the Undifferentiated Properties of Germ Cell Tumors
}

Noriyuki Uema, ${ }^{*}$ Takako Ooshio, ${ }^{*}$ Kenichi Harada, ${ }^{\dagger}$ Masako Naito, ${ }^{\ddagger}$ Kazuhito Naka, ${ }^{*}$ Takayuki Hoshii, ${ }^{*}$ Yuko Tadokoro, ${ }^{*}$ Kumiko Ohta, ${ }^{*}$ Mohamed A.E. Ali, ${ }^{*}$ Miyuki Katano, ${ }^{\S}$ Tomoyoshi Soga, ${ }^{\top}$ Yasuni Nakanuma, ${ }^{\dagger}$ Akihiko Okuda, ${ }^{\S}$ and Atsushi Hirao*

From the Division of Molecular Genetics, * Cancer and Stem Cell Program, Cancer Research Institute, and the Department of Human Pathology, ${ }^{\dagger}$ Graduate School of Medicine, Kanazawa University, Kanazawa; the Department of Anatomy, ${ }^{\ddagger}$ Nihon University School of Dentistry, Tokyo; the Division of Developmental Biology, ${ }^{\S}$ Research Center for Genomic Medicine, Saitama Medical University, Saitama; and the Institute for Advanced Biosciences, ${ }^{\boldsymbol{}}$ Keio University, Yamagata, Japan

Accepted for publication April 30, 2013.

Address correspondence to Atsushi Hirao, M.D., Division of Molecular Genetics, Cancer Research Institute, Kanazawa University, Kakuma-machi, Kanazawa, Ishikawa, Japan. E-mail: ahirao@staff.kanazawa-u. ac.jp.

\begin{abstract}
Nucleostemin (NS) is a nucleolar GTP-binding protein that is involved in ribosomal biogenesis and protection of telomeres. We investigated the expression of NS in human germ cell tumors and its function in a mouse germ cell tumor model. NS was abundantly expressed in undifferentiated, but not differentiated, types of human testicular germ cell tumors. NS was expressed concomitantly with OCT3/4, a critical regulator of the undifferentiated status of pluripotent stem cells in primordial germ cells and embryonal carcinomas. To investigate the roles of NS in tumor growth in vivo, we used a mouse teratoma model. Analysis of teratomas derived from embryonic stem cells in which the NS promoter drives GFP expression showed that cells highly expressing NS were actively proliferating and exhibited the characteristics of tumor-initiating cells, including the ability to initiate and propagate tumor cells in vivo. NS-expressing cells exhibited higher levels of GTP than non-NS-expressing cells. Because NS protein is stabilized by intracellular GTP, metabolic changes may contribute to abundant NS expression in the undifferentiated cells. OCT3/4 deficiency in teratomas led to loss of NS expression, resulting in growth retardation. Finally, we found that teratomas deficient in NS lost their undifferentiated characteristics, resulting in defective tumor proliferation. These data indicate that abundant expression of NS supports the undifferentiated properties of germ cell tumors. (Am J Pathol 2013, 183: 592-603; http://dx.doi.org/10.1016/j.ajpath.2013.04.018)
\end{abstract}

Testicular germ cell tumors (TGCTs) are the most common solid tumor in young adult males. ${ }^{1,2}$ Histologically, TGCTs consist of two groups: seminomas and nonseminomas. The nonseminomas include embryonal carcinoma (undifferentiated), teratoma (differentiated), and yolk sac tumor and choriocarcinoma (extra-embryonic). TGCTs are thought to be initiated in utero as intratubular germ cell neoplasias unclassified, which originate from developing germ cells, primordial germ cells (PGCs), or gonocytes.

PGCs are derived from epiblasts during early embryogenesis. ${ }^{3}$ Epiblasts are pluripotent cells that differentiate to form all three layers of the trilaminar germ disk in a process called gastrulation. Consistently, pluripotent stem cell lines, termed epiblast stem cells, can be established from epiblasts in vitro. ${ }^{4,5}$ In mice, PGCs become identifiable as a cluster of cells at the base of the allantois at 7.25 days after coitus (dpc). ${ }^{3}$ The PGCs express OCT3/4, which support pluripotency. By $11.5 \mathrm{dpc}$, PGCs migrate from the allantois through the hindgut and settle in the gonadal ridge. By 13.5 dpc, PGCs start to display sexually dimorphic patterns of development. In males, PGCs become surrounded by differentiating Sertoli cells and grow continuously until 16.5 $\mathrm{dpc}$, when they undergo mitotic arrest and become gonocytes. $^{6}$ The differentiation of a PGC into a gonocyte restricts its subsequent developmental potential to the generation of male germ cells and is associated with down-regulation of

\footnotetext{
Supported by the Project for Development of Innovative Research on Cancer Therapeutics (P-DIRECT) and by a Grant-in-Aid for Scientific Research on Innovative Areas, both from the Ministry of Education, Culture, Sports, Science and Technology, Japan (A.H.), and by a Grant-inAid for Japan Society for the Promotion of Science fellows (T.O.).

N.U. and T.O. contributed equally to this work.
} 
markers of pluripotency. ${ }^{7,8}$ TGCTs and PGCs or gonocytes have similar gene expression profiles. ${ }^{9}$ Embryonal carcinomas highly express genes that support pluripotency of embryonic stem (ES) cells, including genes for OCT3/4, SOX-2, and NANOG. ${ }^{10,11}$ OCT3/4 and NANOG are sensitive and specific markers for primary seminoma and embryonal carcinoma, whereas SOX-2 is not expressed in seminomas. ${ }^{10}$ These data suggest that the differences among the subtypes of TGCTs may depend on the differentiation status of the tumor.

Nucleostemin (NS), alias guanine nucleotide-binding protein-like 3 (GNL3), is a nucleolar GTP-binding protein that is expressed preferentially in the nucleolus ${ }^{12}$ but it can also shuttle to and from the nucleoplasm. ${ }^{13} \mathrm{NS}$ belongs to the class of nucleolar GTPases that includes yeast Nug1, which exports pre-60S ribosomal subunits out of the nucleolus. ${ }^{14} \mathrm{In}$ Caenorhabditis elegans, $n s t-1$ mutants exhibit reduced rRNA levels, suggesting a critical role for NS in ribosome biogenesis. ${ }^{15}$ NS knockdown apparently delays processing of $32 \mathrm{~S}$ pre-rRNA into 28S rRNA and is accompanied by a substantial decrease both in protein synthesis and in the levels of rRNAs and some mRNAs. ${ }^{16} \mathrm{NS}$ is also involved in regulating telomere integrity. NS and another protein in the same family, GNL3-like (GNL3L), interact with one of the telomeric proteins, telomeric repeat-binding factor 1 (TRF1), preventing telomere damage. ${ }^{17-19} \mathrm{NS}$ and GNL3L form a complex with the telomerase catalytic subunit, human telomerase reverse transcriptase (hTERT). ${ }^{20} \mathrm{NS}$ deficiency in mice is early embryonic lethal, ${ }^{17,21}$ and NS thus plays a critical role in fetal development in vivo. NS was originally reported to be highly expressed in stem cells from several different tissues, including ES cells, immature hematopoietic cells, and neural stem/progenitor cells. ${ }^{12}$ A study using tetracycline (Tet)inducible NS-deficient ES cells showed that NS is essential for the survival of ES cells. ${ }^{22}$

Our research group has previously characterized NS expression in murine male germ cells. ${ }^{23}$ In that study, NS protein was highly expressed in the nucleoli of PGCs. In addition, we successfully identified NS-expressing neonatal germ cells as spermatogonial stem cells with long-term repopulating capacity. In the present study, we investigated the expression pattern of NS in human germ cell tumors and its function in a mouse teratoma model and found that NS is essential for maintaining the undifferentiated status of germ cell tumors.

\section{Materials and Methods}

\section{Animals}

The NS-GFP transgenic mice were generated as described previously. ${ }^{23}$ BALB/c nu/nu mice (6 to 8 week old males) used as xenograft recipients were purchased from Sankyo Labo Service (Tokyo, Japan). All procedures were performed in accordance with the animal care guidelines of Kanazawa University, Kanazawa, Japan. For analysis of timed pregnant mice, the date the vaginal plug was observed was defined as $0.5 \mathrm{dpc}$ of gestation.

\section{Human Samples}

Tissue microarray sections consisting of human samples from patients with germ cell tumors (catalog no. TE2081) and of human fetal tissue (catalog no. BE01015) were purchased from US Biomax (Rockville, MD). For detailed immunohistochemical analysis, formalin-fixed, paraffinembedded sections of surgically resected specimens from 13 germ cell tumors ( 4 seminomas, 4 mature teratomas, and 5 mixed germ cell tumors composed of teratoma and embryonal carcinoma) were obtained from surgical specimens in the Department of Human Pathology, Kanazawa University School of Medicine. All human materials and protocols were approved by the ethics committees of Kanazawa University. Informed consent was obtained from all patients at the time of their surgery. Surgical human specimens were immediately fixed in $10 \%$ neutral-buffered formalin and were embedded in paraffin. Serial sections (4 $\mu \mathrm{m}$ thick) were prepared from each formalin-fixed, paraffinembedded block. Several of the sections were routinely stained for histological evaluation, and the remainder were processed for immunohistochemistry.

\section{Cell Culture}

Mouse ES cells (E14K) were maintained on a layer of mitomycin $\mathrm{C}-$ treated mouse embryonic fibroblasts in KnockOut Dulbecco's modified Eagle's medium supplemented with 15\% fetal bovine serum, $1 \%$ nonessential amino acids, $2 \mathrm{mmol} / \mathrm{L}$ L-glutamine, 50 units $/ \mathrm{mL}$ penicillin plus $50 \mu \mathrm{g} / \mathrm{mL}$ streptomycin, $55 \mu \mathrm{mol} / \mathrm{L}$ 2-mercaptoethanol (all from Life Technologies-Invitrogen, Carlsbad, CA), and 1000 units $/ \mathrm{mL}$ leukemia inhibitory factor (ESGRO; Millipore-Chemicon International, Temecula, CA). The NS-GFP mouse ES cells were established by transfection of an NS-GFP fragment ${ }^{23}$ into parental ES cells by electroporation followed by subcloning. For labeling of ES cells with orange fluorescence, we transfected the NS-GFP ES cells with a Kusabira Orange expression vector (CAG-KO), in which Kusabira Orange cDNA (Medical \& Biological Laboratories, Nagoya, Japan) was cloned into pCAGGS vector plasmid. ES cells with Tet-inducible OCT3/4 deficiency (ZHBTcH4), ${ }^{24}$ ES cells with Tet-inducible NS deficiency, ${ }^{22}$ and control ES cells $\left(\right.$ ERBTcH3) ${ }^{22}$ were maintained without feeder cells, as described previously. ${ }^{22,24}$ These ES cells were cultured with Glasgow minimum essential medium (Sigma-Aldrich, St. Louis, MO) supplemented with $10 \%$ fetal bovine serum, $1 \%$ nonessential amino acids, $2 \mathrm{mmol} / \mathrm{L} \mathrm{L}$-glutamine, $50 \mathrm{U} / \mathrm{mL}$ penicillin plus $50 \mathrm{mg} / \mathrm{mL}$ streptomycin, $1 \mathrm{mmol} / \mathrm{L}$ sodium pyruvate (Gibco), $55 \mathrm{mmol} / \mathrm{L}$ 2-mercaptoethanol, and $1000 \mathrm{U} / \mathrm{mL}$ leukemia inhibitory factor. The differentiation of ES cells was prevented by passaging the cells every 2 or 3 days. For Western blotting analysis, ES cells were incubated in Glasgow minimum 
essential medium containing $10 \mu \mathrm{g} / \mathrm{mL}$ Doxycycline (DOX) (Sigma-Aldrich).

\section{Mouse Teratoma Model}

All ES cells were trypsinized and resuspended in 1:1 PBS/ Matrigel (BD Biosciences, San Jose, CA). Viable ES cells $\left(1 \times 10^{6}\right.$ to $5 \times 10^{6}$ cells in $\left.100 \mu \mathrm{L}\right)$ were injected subcutaneously into the left and right dorsal flanks of BALB/c nu/ nu mice. The mice were monitored for 5 weeks for teratoma formation. Any teratoma observed was measured with calipers, and size was calculated as length $(\mathrm{mm}) \times$ width $(\mathrm{mm})$. When appropriate, mice were given $0.2 \mathrm{mg} / \mathrm{mL}$ Dox (SigmaAldrich) in drinking water.

\section{Histology and Immunohistochemistry}

For immunohistochemistry using human specimens, including those on tissue array, the deparaffinized and rehydrated sections were microwaved in citrate buffer $(\mathrm{pH}$ 6.0) for OCT3/4 or EDTA buffer ( $\mathrm{pH} 9.0$ ) for NS in a microwave oven for 20 minutes. After endogenous peroxidase was blocked, these sections were incubated at $4^{\circ} \mathrm{C}$ overnight with antibodies against OCT3/4 or NS (both from Abcam, Cambridge, UK) and then at room temperature for 1 hour with anti-rabbit IgG conjugated to a peroxidase-labeled dextran polymer (N-Histofine Simple Stain MAX PO kit; Nichirei Bioscience, Tokyo, Japan). After a benzidine reaction, the sections were lightly counterstained with hematoxylin. Mouse teratomas were fixed with $4 \%$ paraformaldehyde at $4{ }^{\circ} \mathrm{C}$ overnight and embedded in paraffin. For some experiments, testes and teratomas were fixed with periodate-lysine paraformaldehyde for 1 hour and dehydrated with 15\% sucrose for 3 hours. Sections fixed with periodatelysine paraformaldehyde were embedded in optimal cutting temperature frozen-embedding medium (OCT Tissue-Tek; Sakura Finetek, Tokyo, Japan). Sections were immunostained with the following primary antibodies: anti-NS (Abcam and Novus Biologicals, Littleton, CO), anti-OCT3/4 (Santa Cruz Biotechnology, Santa Cruz, CA; BD Pharmingen, San Diego, CA; and Abcam), anti-Ki-67 (BD Biosciences), antibromodeoxyuridine (anti-BrdU) (Calbiochem; Merck Millipore, Darmstadt, Germany), and anti-GFP (Medical \& Biological Laboratories and Aves Labs, Tigard, OR). The staining signals in paraffin-embedded sections were visualized with a horseradish peroxidase-conjugated secondary antibody (GE Healthcare, Chalfont St Giles, UK, and Dako, Carpinteria, CA) and a coloring reaction using a 3,3'-diaminobenzidine (DAB) peroxidase substrate kit (Vector Laboratories, Burlingame, CA), counterstained with hematoxylin, and viewed using a microscope (Axio Imager A1; Carl Zeiss, Jena, Germany). The staining signals in frozen sections were visualized with Alexa Fluor dye-conjugated secondary antibodies: anti-mouse IgG, anti-rabbit IgG, or anti-goat IgG (Life Technologies-Invitrogen). For visualization of nuclei, specimens were stained with TOTO-3 dye (Life Technologies-Invitrogen). Immunostaining was visualized under a confocal microscope (FV1000; Olympus, Tokyo, Japan).

\section{Flow Cytometry}

To investigate the expression of GFP, dissociated cells were analyzed by flow cytometry. In brief, teratomas were dissected and incubated with 1\% collagenase type B (Roche Diagnostics, Meylan, France), $2.5 \mathrm{mmol} / \mathrm{L} \mathrm{CaCl}_{2}$, and $1 \mathrm{unit} / \mathrm{mL}$ Dispase II (Roche Diagnostics) in PBS and were dissociated with a pipetting procedure. Dissociated teratoma cells were stained with phycoerythrin-conjugated anti-CD45 and anti-Ter119 antibodies (BD Pharmingen). CD $45^{+}$and Ter $119^{+}$cells were negatively selected on an LD MACS column using anti-phycoerythrin microbeads (Miltenyi Biotec, Bergisch Gladbach, Germany). Finally, the flowthrough fraction was incubated with $1 \mu \mathrm{g} / \mathrm{mL}$ propidium iodide to allow the removal of dead cells. Teratoma cell sorting and analysis were performed using a FACSAria fluorescence-activated cell sorting system (BD Biosciences) and a JSAN cell sorter (Bay Bioscience, Kobe, Japan). Sorted cells were resuspended in PBS containing 10\% fetal bovine serum or KnockOut Dulbecco's modified Eagle's medium, and were prepared for further analysis.

\section{Colony Assay and Alkaline Phosphatase Assay}

Cells fractionated by flow cytometry were plated at 3000 cells per well in 24-well dishes. Colonies were visualized and counted after 1 week. The colonies were rinsed three times with PBS and fixed with $4 \%$ paraformaldehyde for 10 minutes at $4^{\circ} \mathrm{C}$. The fixed colonies were washed with Tris-buffered saline and were measured with alkaline phosphatase (ALP) staining. ALP activity was detected with a fuchsin ${ }^{+}$substratechromogen system (Dako, Glostrup, Denmark).

\section{Real-Time PCR}

RNA samples were purified from fractionated teratoma cells using an RNeasy kit (Qiagen, Valencia, CA) and reversetranscribed using an Advantage RT-for-PCR kit (Clontech Laboratories, Mountain View, CA). Real-time RT-PCR was performed with an Mx3000P quantitative PCR system (Stratagene, La Jolla, CA) and SYBR premix Ex Taq (Takara, Shiga, Japan), according to the manufacturer's recommended protocol. The following primers were used: GAPDH forward 5'-ACCACAGTCCATGCCATCAC-3' and reverse $5^{\prime}$-TCCACCACCCTGTTGCTGTA-3'), NS forward 5'-GAGTGGACAGGTGCCTCATTAGGTTACT- $3^{\prime}$ and reverse $5^{\prime}$-GATGGCTTACCTGCTGTTGATTGCTC-3', and OCT3/4 forward $5^{\prime}$-GGCGTTCTCTTTGGAAAGGTGTTC- $3^{\prime}$ and reverse $5^{\prime}$-CTCGAACCACATCCTTCTCT- $3^{\prime}$.

\section{Quantification of Metabolites}

For capillary electrophoresis time-of-flight mass spectrometry (CE-TOFMS) analysis, $8 \times 10^{5}$ NS-GFP ${ }^{\text {neg }}$, NS-GFP ${ }^{\text {low }}$, 
or NS-GFP ${ }^{\text {high }}$ cells from teratomas were lysed to extract metabolites. Metabolomic profiling and data analysis were performed twice, as described previously. ${ }^{25,26}$

\section{BrdU Incorporation in Vivo}

For BrdU labeling experiments, mice were injected intraperitoneally with $100 \mathrm{mg} / \mathrm{kg}$ body weight BrdU (SigmaAldrich), and the tissues were removed 2 hours later. Detection of BrdU-labeled cells was achieved with a BrdU labeling kit (Calbiochem; Merck Millipore), according to the manufacturer's instructions.

\section{Western Blotting Analysis}

ES cells were lysed with cell lysis buffer $(150 \mathrm{mmol} / \mathrm{L} \mathrm{NaCl}$, $50 \mathrm{mmol} / \mathrm{L}$ Tris-HCl pH 8.0, $1 \%$ NP-40 detergent, and Roche Diagnostics protease inhibitor cocktail); these were then used as total cell lysates. Protein concentrations were measured with a Pierce BCA protein assay (Thermo Fisher Scientific, Rockford, IL), and equal amounts of protein were separated by SDS-PAGE and transferred onto polyvinylidene difluoride membranes. Membranes were blocked with 5\% nonfat milk in PBS containing Tween 20 for 1 hour at room temperature. Membranes were then incubated with a goat anti-NS antibody (1:1000; Neuromics, Edina, MN) or an anti-OCT3/4 antibody (1:2000; BD Pharmingen) for 16 hours at $4^{\circ} \mathrm{C}$, or a mouse anti- $\beta$-actin antibody (1:1000; Sigma-Aldrich) for 1 hour at room temperature. Immune complexes were detected using peroxidase-conjugated secondary antibodies (1:1000; 30 minutes incubation at room temperature; GE Healthcare and Dako) and an ECL Prime Western blotting detection system (GE Healthcare).

\section{Detection of Apoptosis}

To detect apoptosis in vivo, freshly isolated teratomas were immediately fixed with $4 \%$ paraformaldehyde, and tissue sections were prepared. The sections were stained by using a DeadEnd colorimetric TUNEL system (Promega, Madison, WI), according to the manufacturer's instructions.

\section{Statistical Analysis}

Statistical significance was determined using the unpaired Student's $t$-test.

\section{Results}

Abundant Expression of NS in Undifferentiated, but Not Differentiated, Germ Cell Tumors in Human TGCTs

To analyze expression of NS in germ cell tumors, we stained tissue sections of human TGCTs (including seminomas, embryonal carcinomas, and mixed germ cell tumors) with an anti-NS antibody. NS expression was detected in 18/28 (64\%) embryonal carcinomas and in 52/86 (60\%) seminomas (Figure 1, Supplemental Figure S1, and Supplemental Table S1). NS protein was localized mainly in nuclei, and was not present in the cytoplasm. In most $\mathrm{NS}^{+}$cells, NS protein was detected in both the nucleoplasm and nucleoli (Figure 1 and Supplemental Figure S1). There were no remarkable differences in expression pattern or abundance of NS between embryonal carcinomas and seminomas. NS expression was detected in undifferentiated components, including the embryonal carcinoma portion of all mixed germ cell tumors, and most tumor cells in the embryonal carcinoma component highly expressed NS (Figure 2, A and B). NS was not expressed in most interstitial cells, but was expressed in a few undifferentiated mesenchymal cells within the embryonal carcinoma (Figure 2, A and B). NS expression was not detected in the well-differentiated intestine-like component of a mature teratoma (Figure 2C), but weak nucleolar expression was seen in epidermal squamous cells (Figure 2D). Thus, NS was highly expressed in the embryonal carcinoma component, but not in well-differentiated mature teratoma tissues. Because it has been reported that OCT3/4, which is a critical regulator of the undifferentiated status of ES cells, controls the malignant fate of germ cell tumors, ${ }^{27}$ we next compared NS expression with OCT3/4 expression. OCT3/4 protein was detected in all mixed germ cell tumors. It was highly expressed in the embryonal carcinoma component (Figure 2E), but not in the well-differentiated mature teratoma components, including the intestine-like cells and epidermal cells (Supplemental Figure S2). Double staining with anti-OCT3/4

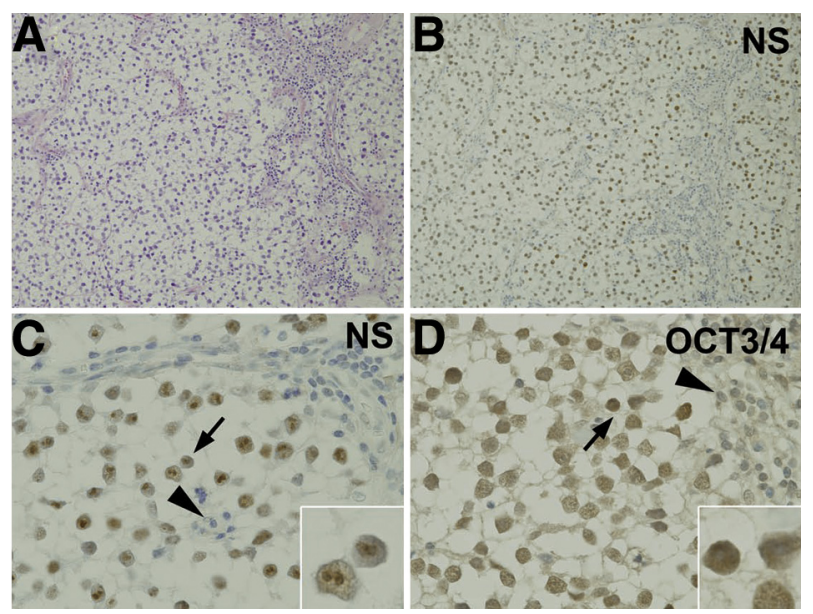

Figure $1 \mathrm{NS}$ and 0CT3/4 expression in human seminomas. Representative sections of $\mathrm{NS}^{+}$seminomas. Sections were stained with an anti-NS or anti-0CT3/4 antibody, followed by a DAB peroxidase reaction; sections were counterstained with hematoxylin. A: Seminoma. H\&E stain. B: Immunohistochemistry for NS. Most tumor cells in the seminoma are positive for NS. C: Higher magnification of a section stained with anti-NS antibody. NS is strongly expressed within the nuclei and nucleoplasm of seminoma cells (arrow). Infiltrating lymphocytes within tumor nests are negative for NS (arrowhead). D: Immunohistochemistry for 0CT3/4. Nuclei of tumor cells within a seminoma are positive for $0 \mathrm{CT} 3 / 4$ (arrow). Infiltrating lymphocytes within tumor nests are negative for 0CT3/4 (arrowhead). The insets show digitally enlarged images of regions with cells indicated by arrows in the insets. Original magnification: $\times 100(\mathbf{A}$ and $B) ; \times 400($ and D). 


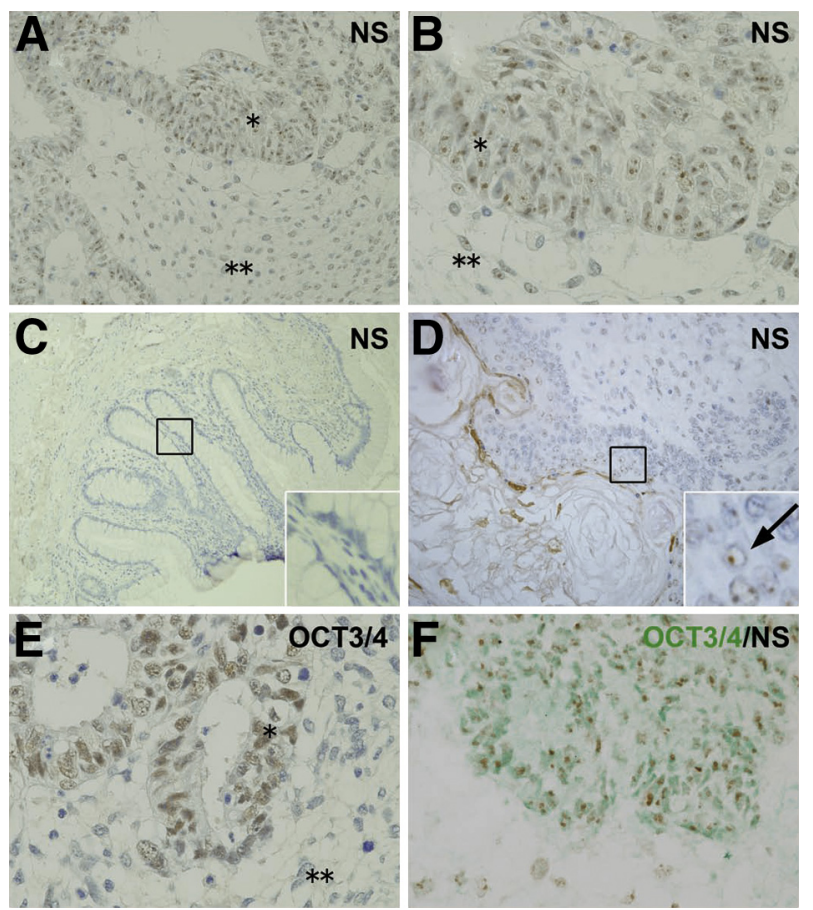

Figure 2 Abundant expression of NS in undifferentiated cells in human mixed-type germ cell tumors. Expression of NS and OCT3/4 in human germ cell tumors of mixed type (both embryonal carcinoma and mature teratoma cells). Sections were stained with an anti-NS or anti-0CT3/4 antibody, followed by a DAB peroxidase reaction; sections were counterstained with hematoxylin. A: Immunohistochemistry for NS in the embryonal carcinoma component. Most tumor cells of the embryonal carcinoma are positive for NS (asterisk), as are a few undifferentiated mesenchymal cells (double asterisk). B: Higher magnification of a portion of $\mathbf{A}$. NS is expressed in the nucleoli of embryonal carcinoma cells (asterisk) and undifferentiated mesenchymal cells (double asterisk). C and D: Immunohistochemistry for NS in the intestine-like component (C) and in squamous cells of the epidermis (D). No positive cells were found in the intestine-like component. Weak nucleolar expression was found in the epidermal squamous cells. The insets show digitally enlarged images of the boxed regions. E: Immunohistochemistry for OCT3/4. Many $0 \mathrm{CT} 3 / 4^{+}$cells were seen in the embryonal carcinoma (asterisk) but none in the undifferentiated mesenchymal components (double asterisk). F: Double immunohistochemical staining for NS (brown) and 0CT3/4 (green). Most embryonal carcinoma cells express both NS and 0CT3/4. Original magnification: $\times 200(\mathbf{A}$ and $\mathbf{C}) ; \times 400(\mathbf{B}$ and $\mathbf{D}-\mathbf{F})$.

and anti-NS antibodies clearly showed that both proteins were expressed in the same cells (Figure 2F). Thus, coexpression of $\mathrm{NS}$ and OCT3/4 was observed mainly in undifferentiated germ cell tumors (embryonal carcinomas).

\section{PGC-Specific Expression of NS}

Because TGCTs possibly originate from PGCs, we evaluated NS expression in developing gonadal tissues in mice. Previously, we had generated transgenic reporter mice expressing GFP under the control of the NS promoter (NSGFP Tg mice) and reported that the GFP successfully reflects NS expression in the developing testes. ${ }^{23}$ Consistent with that earlier study, we found particular cell populations expressing high levels of GFP (corresponding to NSexpressing cells) in the gonadal ridge at $10.5 \mathrm{dpc}$ and in embryonic testes at $14.5 \mathrm{dpc}$ (Figure 3A). Approximately $60 \%$ of NS-GFP-positive cells were OCT3/4 $4^{+}$at $10.5 \mathrm{dpc}$ $\left(\mathrm{Oct}^{+} / \mathrm{GFP}^{+}, 62.73 \pm 7.14 \% ; \mathrm{Oct}^{-} / \mathrm{GFP}^{+}, 35.12 \pm\right.$ $10.87 \%$; $\mathrm{Oct}^{+} / \mathrm{GFP}^{-}, 2.15 \pm 3.72 \% ; n=3$ ). At $14.5 \mathrm{dpc}$, most NS-GFP-positive cells were OCT3/4 ${ }^{+}\left(\mathrm{Oct}_{4}{ }^{+} / \mathrm{GFP}^{+}\right.$, $97.50 \pm 2.23 \%$; $\mathrm{Oct}^{-} / \mathrm{GFP}^{+}, 2.49 \pm 2.23 \%$; $\mathrm{Oct}^{+}{ }^{+} / \mathrm{GFP}^{-}$, $0 \% ; n=3$ ). Thus, GFP expression was almost coincident with that of ОСТ3/4 at $14.5 \mathrm{dpc}$; because OCT3/4 is a PGC marker, this indicates that NS is expressed in PGCs. In neonates, OCT3/4 expression dramatically diminished, indicating that there is discrepancy between NS and OCT3/4 in gonocytes. We also analyzed the expression of NS in human embryonic testes. As previously reported, ${ }^{28}$ OCT3/ 4-immunopositive staining was restricted to a particular subset of germ cells (Figure 3B). The staining pattern of NS was similar to that of OCT3/4 (Figure 3B). Double-staining analysis showed that, although some cells expressed OCT3/4 but not NS, NS was expressed only in cells that also expressed OCT3/4 (Figure 3B). Thus, common expression of NS and OCT3/4 in developing gonadal tissues was observed in both mouse and human tissues, indicating that NS is expressed in PGCs.

\section{Characterization of Tumor Cells That Highly Express NS in a Teratoma Model}

ES cells are commonly used to generate teratomas (ie, tumorlike formations containing tissues belonging to all three germ layers), which are used as a model of germ cell tumors. Because mouse teratomas derived from ES cells contain an OCT3/4 undifferentiated cell component, ${ }^{27}$ this model may be similar to human mixed-type germ cell tumors. We therefore chose this model for evaluating NS expression. We established singleclone-derived ES clones containing the NS-GFP fragment and used them to inoculate mice subcutaneously (Figure 4A). Tumors became detectable approximately 2 weeks later and grew continuously until the mice were sacrificed at 5 weeks. The NS-GFP ES cell-derived tumors were identified as teratomas, because several different cell components were included (eg, epithelial cells, muscles, intestine, and neurons; data not shown). In a histological analysis, NS-GFP was highly expressed only in particular areas (Figure 4B). Most cells expressing NS-GFP exhibited high levels of endogenous NS protein (Figure 4C). The NS-GFP-expressing cells also expressed OCT3/4 (Figure 4C), but they did not express the differentiation markers TuJ1 and SMA (Figure 4C). We did not detect metastatic NS-GFP-expressing cells in the recipient mice. The NS-GFP-positive cells appeared to be actively proliferating, based on their Ki-67 positivity (Figure 4C). These data clearly indicate that NS is abundantly expressed in proliferating, undifferentiated cells in the ES-derived mouse teratomas, which is similar to NS expression in human mixedtype teratomas.

To further investigate the characteristics of NS-expressing cells, we dissociated teratoma tissues with collagenase/ trypsin, then analyzed them with flow cytometry. Although 


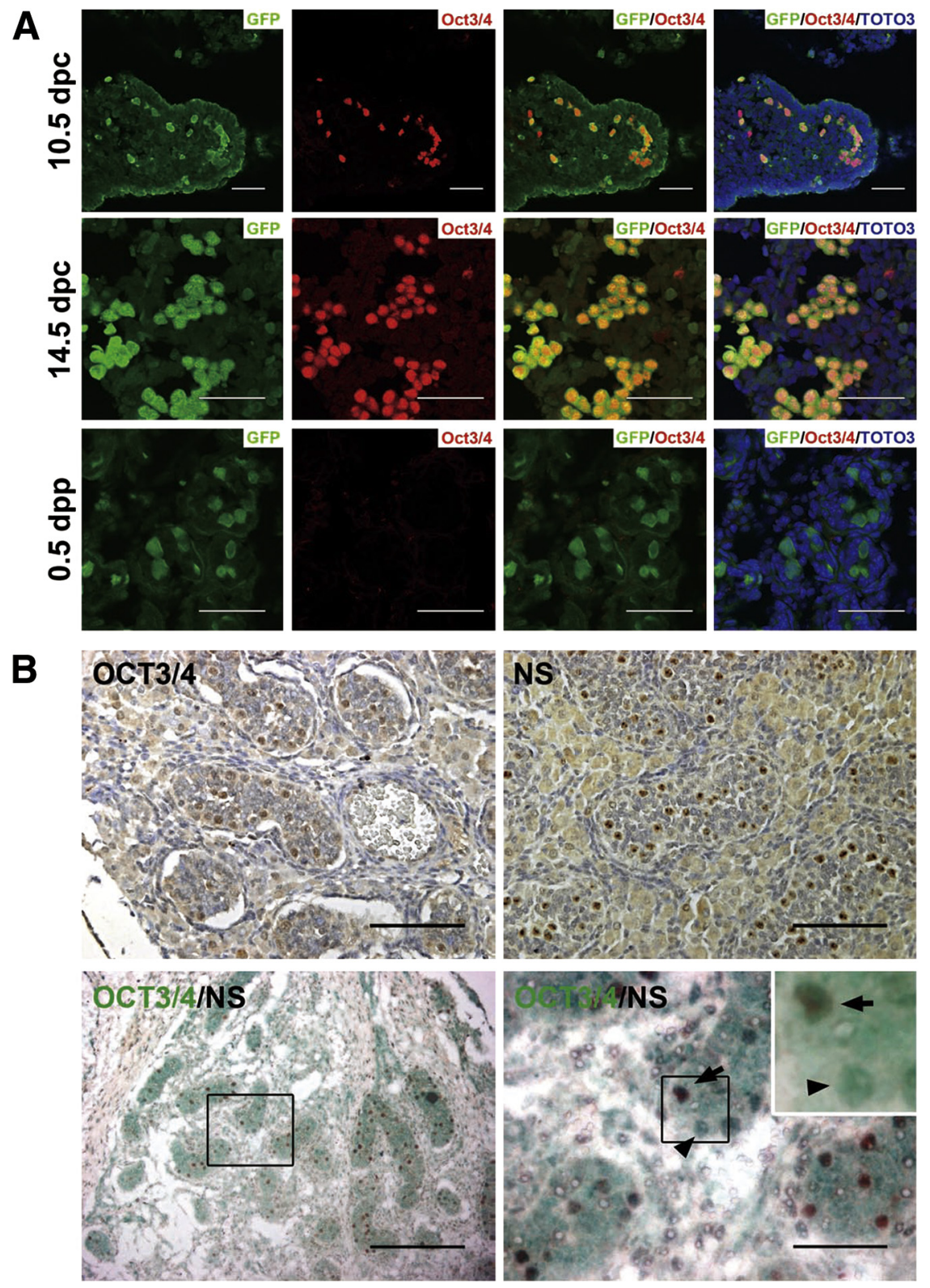

Figure 3 Coexpression of NS and OCT3/4 in mouse and human embryonic testes. A: Immunohistochemical analyses of developing gonad sections from NS-GFP Tg mouse embryos (10.5 and $14.5 \mathrm{dpc}$ ) and neonates [0.5 days after birth (dpp)]. Sections were stained with anti-GFP (green) and anti-0CT3/4 (red) antibodies, and with TOT03 (blue) to visualize nuclei. B: Immunohistochemical analyses of testicular sections from human embryos ( 5 or 6 months of gestation). Sections were stained with an anti-OCT3/4 or anti-NS antibody, followed by a DAB peroxidase reaction (upper panels). Double staining was performed with anti-NS (brown) and anti-0CT3/4 (green) antibodies (lower panels). The sections were counterstained with hematoxylin. The right lower panel is a magnified view of the boxed region in the left lower panel; the boxed region in the right lower panel is shown at higher magnification in the inset. $\mathrm{NS}^{+}$(brown) $/ 0 \mathrm{CT} 3 / 4^{+}$(green) cells are indicated by arrows; NS-negative (no brown staining) $/ 0 \mathrm{CT} 3 / 4^{+}$(green) are indicated by arrowheads. Scale bars: $25 \mu \mathrm{m}$ (A, middle and lower panels), $50 \mu \mathrm{m}$ (A, upper panels, and $\mathbf{B}$, right lower panel); $100 \mu \mathrm{m}$ (B, upper panels); $200 \mu \mathrm{m}$ (B, left lower panel).

the NS-GFP ES cells in our experiments expressed high levels of GFP, the majority of teratoma cells exhibited a lower level of GFP expression (Figure 5A), indicating that GFP expression was down-regulated during teratoma formation. The NS-GFP-positive cells could be fractionated into two populations, based on GFP intensity (Figure 5B). We compared the properties of the NS-GFP ${ }^{\text {neg }}$, NS-GFP ${ }^{\text {low }}$, and NS-GFP ${ }^{\text {high }}$ cell populations. NS-GFP intensity increased as the amount of endogenous NS mRNA increased, confirming that NS-GFP properly reflected the level of NS mRNA expression (Figure 5C). In addition, NS-GFP intensity and OCT3/4 mRNA were correlated, indicating that NS$\mathrm{GFP}^{\text {high }}$ cells are OCT3/4 $4^{+}$undifferentiated cells.

To investigate the functions of the NS-expressing cells, we cultured isolated cells in ES medium in vitro. By day 7 of culture, ES-like cell colonies derived from teratomas had emerged. The NS-GFP ${ }^{\text {high }}$ cells produced higher numbers of
ES-like colonies (identified by expression of ALP, a marker of undifferentiated cells) than did NS-GFP ${ }^{\text {neg }}$ or NS-GFP ${ }^{\text {low }}$ cells (Figure 5D). To evaluate the functions of ES-derived teratoma cells alone, without including cells in the tumor tissues derived from the recipient (host) mice, we established a teratoma model using NS-GFP ES cells labeled with Kusabira Orange fluorescence (Supplemental Figure S3, A and B). Consistent with data in Figure 5D, colony-forming assays with teratoma cells positive for Kusabira Orange showed that NS-GFP ${ }^{\text {high }}$ cells produced high numbers of ESlike colonies (Supplemental Figure S3C). Moreover, NSGFP $^{\text {high }}$ cells formed significantly larger tumors in vivo than did NS-GFP ${ }^{\text {low }}$ cells (Figure 5E). No tumor formation from NS-GFP ${ }^{\text {neg }}$ cells was observed. These data indicate that high NS expression represents undifferentiated status and that at least some NS-expressing cells can function as tumorinitiating cells. 


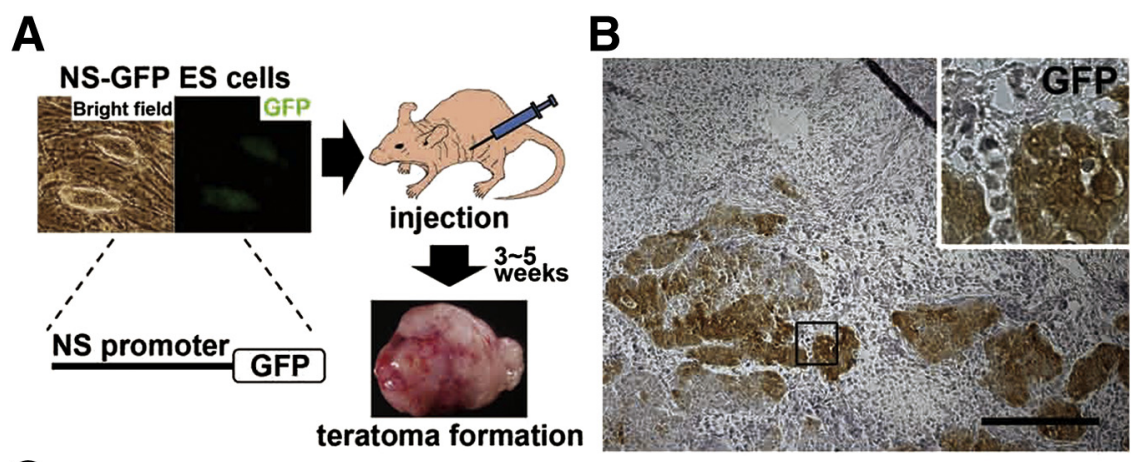

C
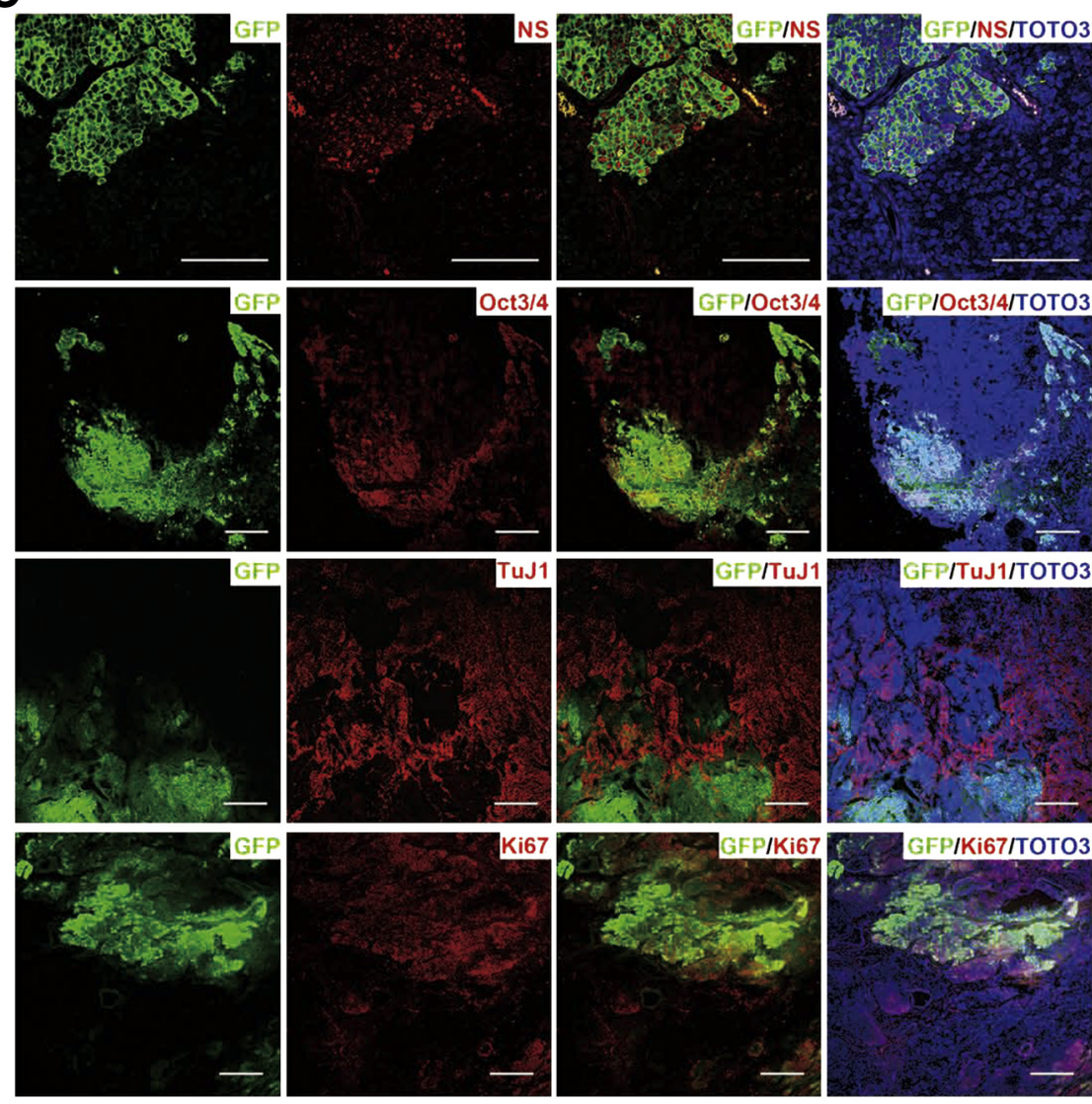

Expression of NS is regulated both transcriptionally and post-translationally. Stabilization of the NS protein is supported by intracellular GTP. ${ }^{29,30}$ These data prompted us to examine whether the undifferentiated cell fractions in the teratomas have a high level of GTP in vivo. We used CETOFMS to evaluate metabolite concentrations ${ }^{25,26}$ in NSGFP $^{\text {neg }}, \mathrm{NS}^{-G F P}{ }^{\text {low }}$, and NS-GFP ${ }^{\text {high }}$ cells. Although there was no significant difference in GTP concentration between NS-GFP ${ }^{\text {high }}$ and NS-GFP ${ }^{\text {low }}$ cells, both NS-GFP ${ }^{\text {high }}$ and NS-GFP ${ }^{\text {low }}$ cells had significantly more GTP than did NS$\mathrm{GFP}^{\text {neg }}$ cells (Figure 5F). These findings suggest that NS protein stability may be supported by GTP in NS-GFP ${ }^{\text {high }}$ and NS-GFP ${ }^{\text {low }}$ cells, but not in NS-GFP ${ }^{\text {neg }}$ cells. Because the amount of NS mRNA in NS-GFP ${ }^{\text {high }}$ cells was greater than in NS-GFP ${ }^{\text {low }}$ cells (Figure 5C), we assumed that the high level of NS protein in NS-GFP ${ }^{\text {high }}$ is supported by
Figure 4 NS is expressed in proliferating cells that exhibit undifferentiated characteristics in a mouse teratoma model. A: Experimental design of a mouse teratoma model using NS-GFP ES cells. GFP expression is driven by the NS gene promoter in the NS-GFP ES cells. The teratomas are generated by injection of NS-GFP ES cells into the dorsal flanks of BALB/c nu/nu mice. In teratomas derived from NS-GFP ES cells, endogenous NS gene expression can be monitored by GFP. B: A representative section of anti-GFP immunohistochemistry in a teratoma derived from NS-GFP ES cells. Sections were stained with an anti-GFP antibody, followed by a DAB peroxidase reaction. The inset shows digitally enlarged image of the boxed region. C: Immunohistochemical analyses of teratomas derived from NS-GFP ES cells. Sections were stained with an anti-GFP antibody (green) and anti-NS, anti-OCT3/4, anti-TuJ1, or anti-Ki67 antibodies (red), followed by T0T03 (blue) to visualize nuclei. Scale bars: $50 \mu \mathrm{m}$ (C, first row); $200 \mu \mathrm{m}$ (B and $\mathbf{C}$, remaining rows). 
A

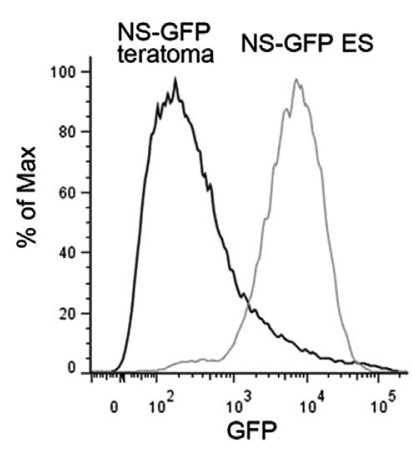

C

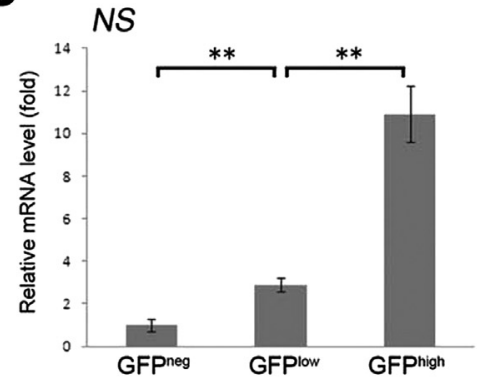

E

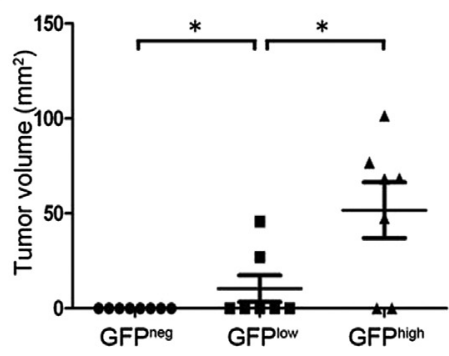

B
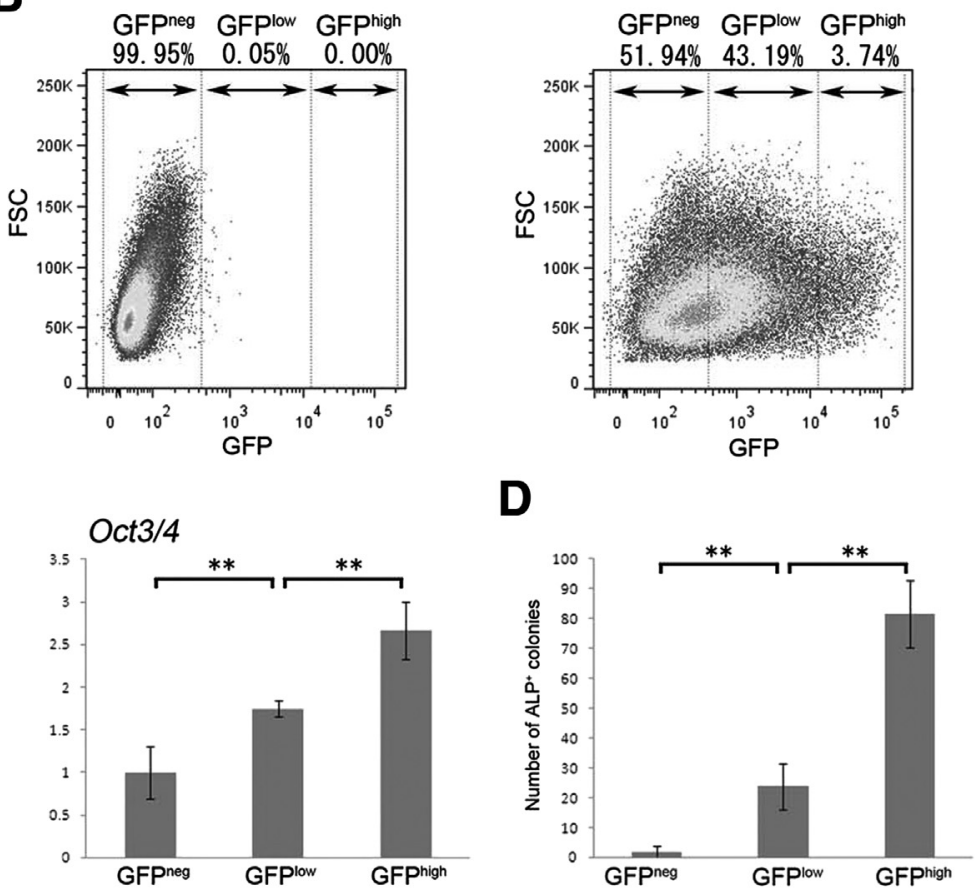

$\mathbf{F}$

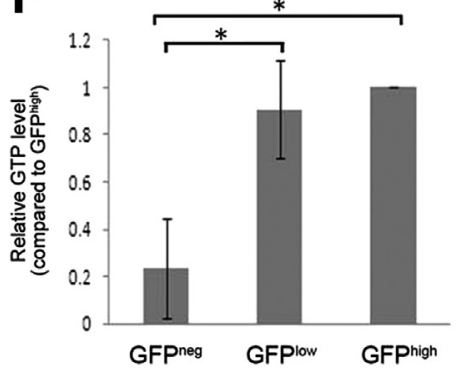

D
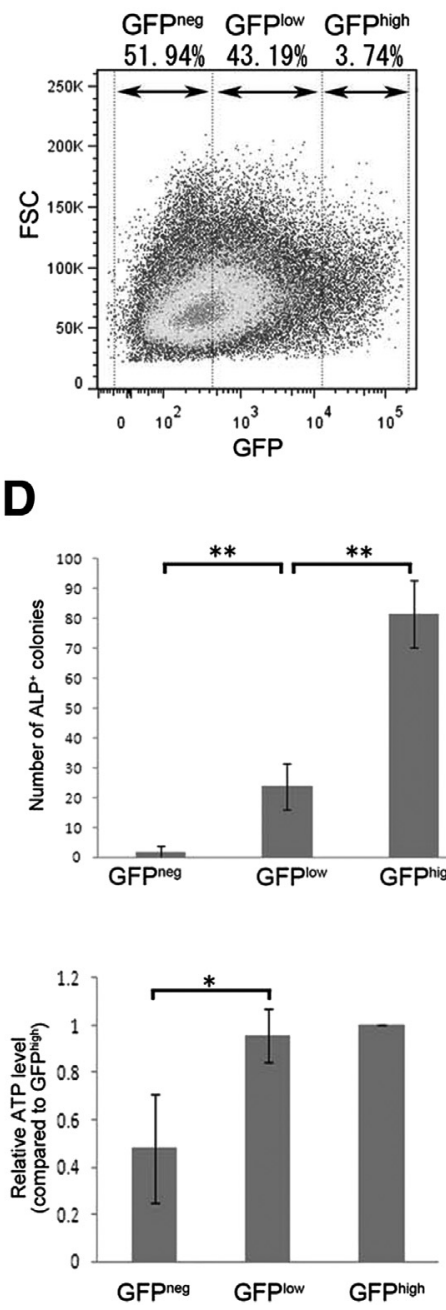

Figure 5 Characterization of NS-expressing cells in a mouse teratoma model. A: Flow cytometry analysis of GFP expression in NS-GFP teratomas and ES cells. The teratomas were generated by injection of NS-GFP ES cells into the dorsal flanks of BALB/c nu/nu mice (Figure 4A). Nonhematopoietic cells from teratoma tissues were isolated by depletion of $\mathrm{CD}_{4} 5^{+}$Ter $119^{+}$cells. Data shown are representative flow cytometry analyses of GFP in CD45 ${ }^{-}{\text {Ter } 119^{-} \text {PI }}^{-}$cells from NS-GFP teratoma cells (black line) and in NS-GFP ES cells (gray line). GFP expression was remarkably down-regulated during tumor formation. B: Flow cytometry analysis of GFP expression in wild-type and NS-GFP teratoma cells. GFP was not detected in wild-type teratomas, but was detected in almost half of the cells in the NS-GFP teratomas. The teratoma cells (nonhematopoietic cells) from the NS-GFP teratomas were fractionated into GFP ${ }^{\text {neg }}$, GFP ${ }^{\text {low }}$, and GFP ${ }^{\text {high }}$ subpopulations. Data are

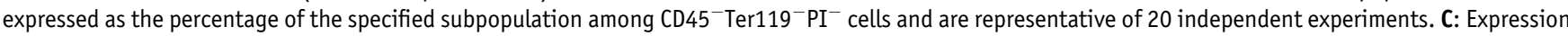
of endogenous NS and OCT3/4 in the NS-GFP subpopulations. Total RNA was purified from the subpopulations (B), and mRNA levels of NS and OCT3/4 were evaluated by quantitative real-time RT-PCR. The RNA data were normalized to the expression of GAPDH. Data are expressed as means \pm SD of GFPlow or GFPhigh values relative to those of GFP ${ }^{\text {eg }}$ cells. D: ALP ${ }^{+}$colony formation of the NS-GFP subpopulations. Fractionated cells (B) were cultured for 7 days, followed by staining with ALP. E: Teratoma formation of the NS-GFP subpopulations in vivo. Fractionated cells (Supplemental Figure S3B) were inoculated subcutaneously in $\mathrm{BALB} / \mathrm{c} \mathrm{nu} / \mathrm{nu}$ mice. The tumor volume was measured 5 weeks later. Teratoma size was calculated as length $(\mathrm{mm}) \times$ width (mm). F: Quantification of metabolites in the NS-GFP subpopulations. GTP and ATP levels were evaluated in the subpopulations (B) by CE-TOFMS analysis. Data are expressed as means \pm SD (C-F) or as both means \pm SD and individual values (E). $n=3(\mathbf{F}) ; n=5(\mathbf{C}) ; n=6(\mathbf{D}) ; n=8$ per group (E). ${ }^{*} P<0.05 ;{ }^{* *} P<0.01$.

$(\mathrm{ZHBTcH} 4){ }^{24}$ Both endogenous alleles of OCT3/4 are disrupted in these ES cells, but OCT3/4 cDNA under the control of a Tet-responsive transcriptional activator is introduced. The exogenous OCT3/4 cDNA is induced in OCT3/4-deficient ES cells in the absence of Tet (Dox), whereas its expression is down-regulated in the presence of Dox. The ES cells thus lose OCT3/4 expression when treated with Tet (forming Tet-induced OCT3/4-deficient ES cells). After teratomas were formed in nude mice by injection of Tet-inducible OCT3/4-deficient ES cells, the mice were administered Dox to eliminate OCT3/4 expression. At day 14 , the OCT $3 / 4$ protein was completely lost in teratoma tissues treated with Dox, but not in control tissues (Figure 6, $\mathrm{A}$ and $\mathrm{B})$. In addition, the OCT3/4-deficient teratoma cells lost $\mathrm{Ki}-67$ expression, indicating that OCT3/4 deficiency resulted in inhibition of proliferation, which is consistent with previous report. ${ }^{27} \mathrm{NS}$ protein was reduced also in the OCT3/4-deficient teratomas (Figure 6B), as were the amounts of OCT3/4 and NS mRNA (Figure 6C). These data indicate that the teratomas that lost the undifferentiated cell 

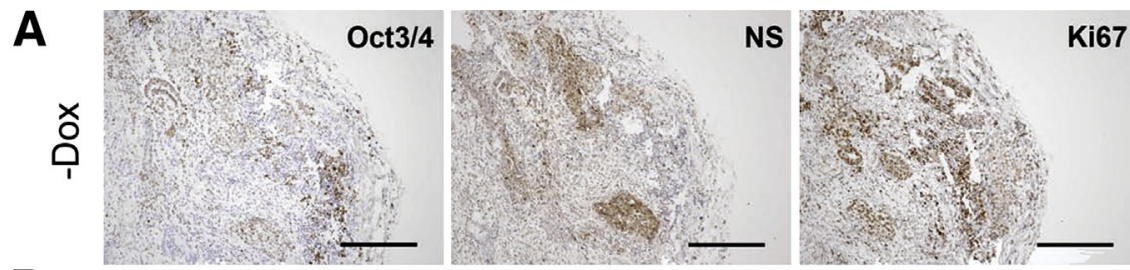

B
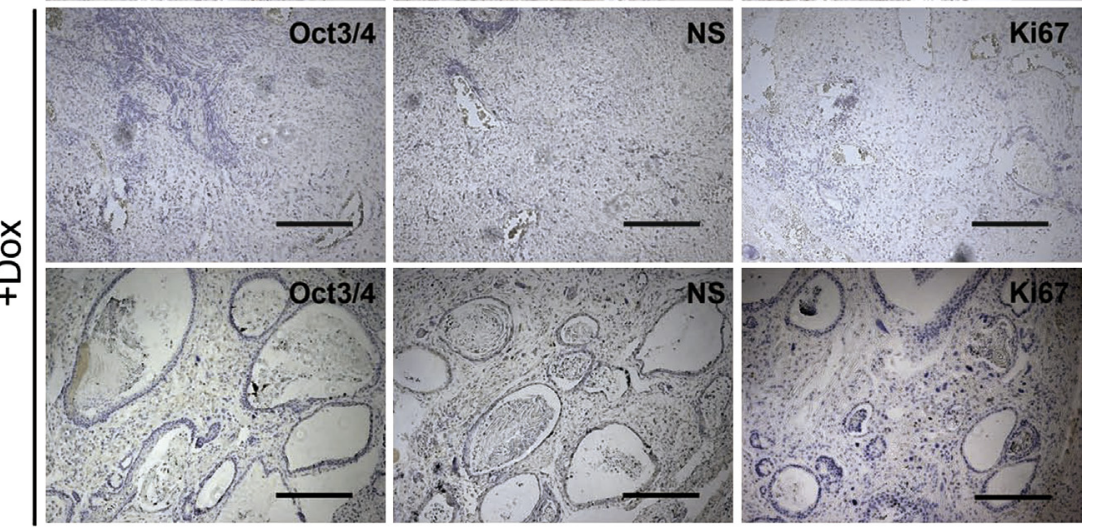

C
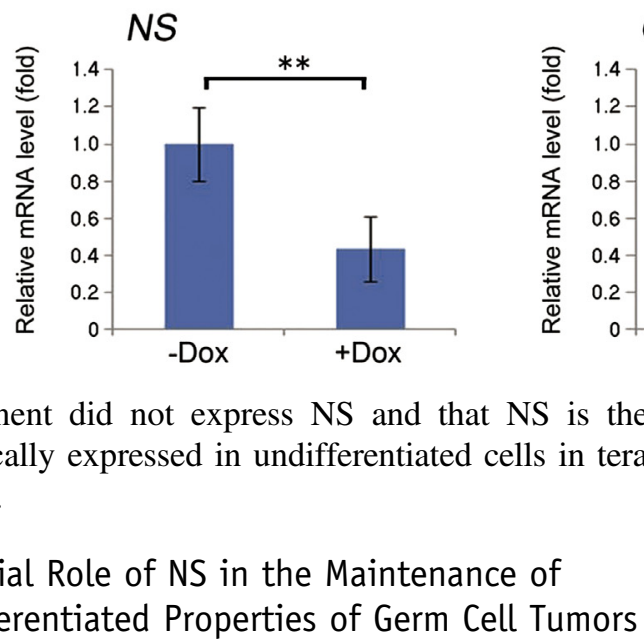

component did not express NS and that NS is therefore specifically expressed in undifferentiated cells in teratomas in vivo.

\section{Essential Role of NS in the Maintenance of Undifferentiated Properties of Germ Cell Tumors}

To investigate the roles of NS in undifferentiated germ cell tumors, we generated teratomas by using Tet-inducible NSdeficient ES cells. The gene for NS can be deleted from ES cells by tetracycline treatment, as in the Tet-induced OCT3/ 4-deficient ES cells described above. ${ }^{22}$ We confirmed that Dox treatment in vitro efficiently reduced NS protein in the ES cells but did not affect OCT3/4, consistent with previous report $^{22}$ (Supplemental Figure S4). When the teratomas formed ( 3 weeks after inoculation), the mice were administered Dox to induce NS deficiency. The histological analysis showed that the Dox administration resulted in loss of the undifferentiated cell components in teratomas derived from the Tet-inducible NS-deficient ES cells (Figure 7A). NS protein clearly disappeared in the teratomas after Dox administration; also, the NS-deficient tumors lost OCT3/4 expression (Figure 7B), and this loss was associated with reduced Ki-67 expression and BrdU incorporation (Supplemental Figure S5, A and B). A TUNEL assay did not show any remarkable induction of apoptosis after NS deletion in vivo (Supplemental Figure S5C). The neuronal marker TuJ1, however, was

\section{Discussion}

Figure 6 Loss of NS in 0CT3/4-deficient teratomas. $\mathbf{A}$ and $\mathbf{B}$ : Immunohistochemical analyses of teratoma sections derived from Tet-inducible OCT3/4-deficient ES cells in immunocompromised (BALB/c nu/nu) mice. After teratoma formation, the mice were administered Dox orally for 14 days. The sections were stained with an anti-0CT3/4, anti-NS, or anti-Ki-67 antibody, followed by a DAB peroxidase reaction. Sections were counterstained with hematoxylin. C: NS and 0CT3/4 mRNA in the teratomas with and without Dox. Total RNA was purified from teratomas, and mRNA levels of NS and OCT3/4 were evaluated with quantitative real-time RT-PCR. RNA data were normalized to expression of GAPDH. Data are expressed as means \pm SD of values of samples with Dox relative to those of samples without Dox. $n=5 .{ }^{*} P<0.01$. Scale bars: $200 \mu \mathrm{m}$.

In the present study, we found similar expression patterns for NS and OCT3/4 in undifferentiated germ cell tumors in humans and in PGCs in both humans and mice (Figures 1, 2, and 3). Because previous gene expression profiling showed that PGCs and germ cell tumors have similar gene expression signatures, ${ }^{9}$ it has been proposed that PGCs are one source of germ cell tumors. Embryonic stages and malignancy are thought to be closely related, because embryonic antigens, such as $\alpha$-fetoprotein, commonly emerge during carcinogenesis. Thus, NS may be a critical link between embryonic development and malignancy.

In the mouse teratoma model, NS was abundantly expressed in proliferating, undifferentiated cells (Figure 4). Furthermore, we clearly demonstrated that NS can be an indicator of tumor-initiating cells (alias cancer stem cells) 
A
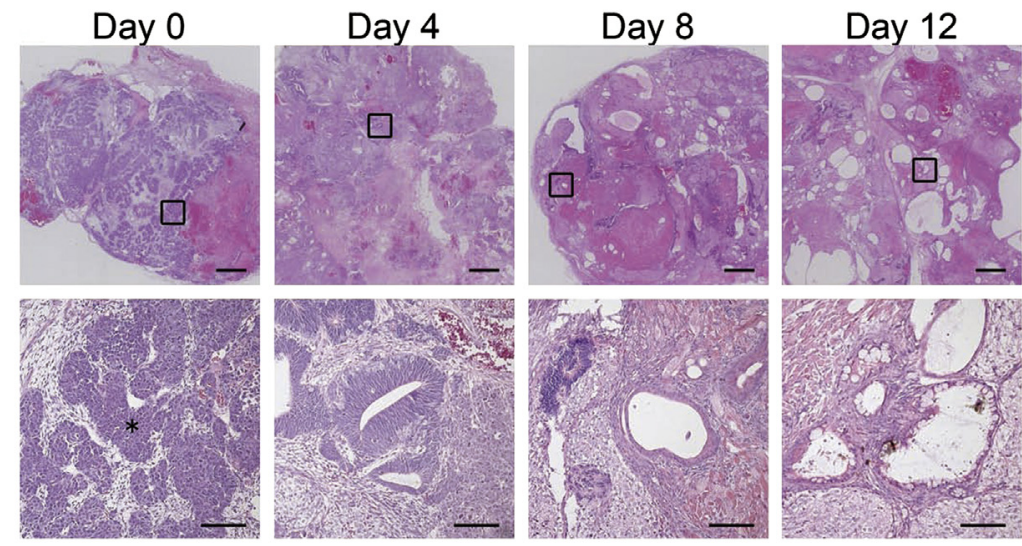

B
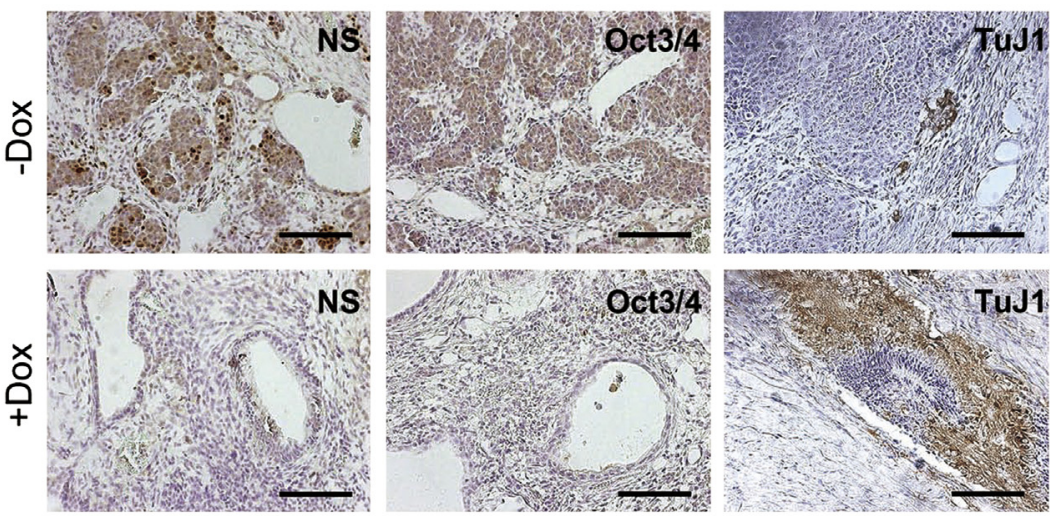

C
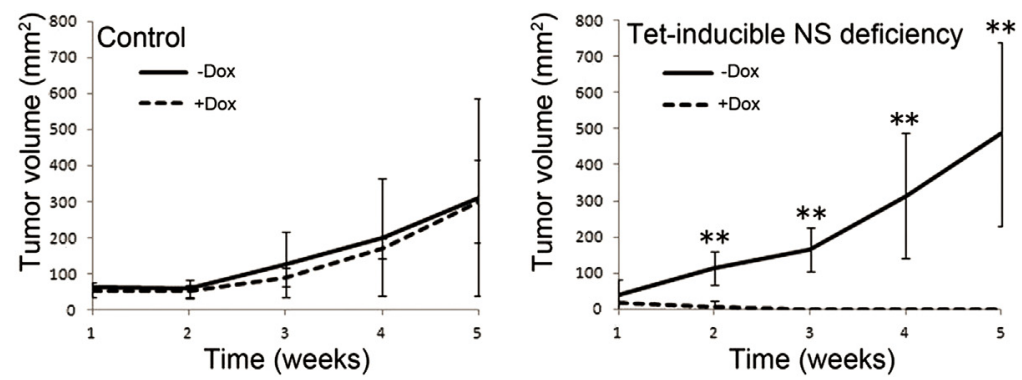

Figure 7 Inhibition of teratoma growth by NS deficiency. A and B: Immunohistochemical analyses of teratoma sections derived from Tet-inducible NSdeficient ES cells in immunocompromised (BALB/C $\mathrm{nu} / \mathrm{nu}$ ) mice. After teratoma formation (3 weeks after inoculation), the mice were given Dox orally. A: Sections of teratomas obtained at days $0,4,8$, and 12 after the initiation of Dox administration, stained with H\&E. The undifferentiated cell component disappeared with Dox treatment. Boxed regions in the upper row are shown at higher magnification in the lower row. Undifferentiated cell components (asterisk) disappear with loss of NS. B: Sections of teratomas treated without or with Dox for 14 days were stained with an anti-NS, anti$0 C T 3 / 4$, or anti-TuJ1 antibody, followed by a DAB peroxidase reaction. Sections were counterstained with hematoxylin. C: Effect of NS deficiency on teratoma formation. The immunocompromised mice were inoculated with control or ES cells with Tetinducible NS-deficiency; Dox was administered orally at the same time. Teratoma size was calculated as length $(\mathrm{mm}) \times$ width $(\mathrm{mm})$. Data are expressed as means \pm SD. $n=8$ per group. ${ }^{*} P<$ 0.01 . Scale bars: $1 \mathrm{~mm}$ (A, upper panels); $100 \mu \mathrm{m}$ (A, lower panels); $200 \mu \mathrm{m}$ (B).
(Figure 5). Although NS was originally reported to be highly expressed in stem cells from several tissues, including ES cells, immature hematopoietic cells, and neural stem/ progenitor cells, ${ }^{12}$ it has also been reported to be expressed in postmitotic, terminally differentiated cells (myotubes and myofibers). ${ }^{31}$ Our research group previously reported abundant NS protein in mature hepatocytes. ${ }^{32}$ Thus, the expression pattern of NS appears to be complex. Furthermore, the NS-GFP reporter system allowed us to identify a specific fraction of neonatal germ stem cells as undifferentiated cells ${ }^{23}$ developing liver stem/progenitor cells, ${ }^{32}$ and neural stem cells. ${ }^{33}$ We also combined the NS reporter system with a mouse brain tumor model and demonstrated the existence of an undifferentiated tumor-initiating cell population in a highly aggressive brain tumor by analyzing GFP fluorescence intensity. ${ }^{33}$ Consistent with the present data, a report using a bacterial artificial chromosome transgenic mouse line expressing GFP from the NS promoter showed that
NS-enriched mammary tumor cells are highly tumorigenic in vitro and in vivo. ${ }^{34}$ Although the mechanisms are still unclear, we assume that there are particular programs that control the promoter activity and that these are commonly upregulated in undifferentiated cells in both normal and malignant tissues.

Loss of NS resulted in decreased OCT3/4 expression in mouse teratomas (Figure 7). This finding may conflict with our other findings in the present study (Supplemental Figure S4) and with those of others, ${ }^{21,22}$ that NS deletion did not affect OCT3/4 expression in embryos and ES cells. NS also appears to be controlled independently of mechanisms involving the OCT3/4-SOX-2 core complex, which is specific for the maintenance of undifferentiated status of ES cells. OCT3/4 has a bipartite POU domain, which mediates DNA binding for the regulation of gene expression networks. ${ }^{35-37}$ A number of studies have shown that OCT3/4 cooperates with SOX-2 to regulate gene expression 
in ES cells. ${ }^{38-41}$ Although a possible HMG/POU motif is present in the NS promoter, ${ }^{42}$ there is no evidence that the OCT3/4-SOX-2 complex binds to the NS locus. ${ }^{43,44}$ There are several possible reasons why NS deletion could lead to loss of OCT3/4 in teratomas. For example, loss of NS may primarily inhibit cell proliferation, thereby inducing differentiation of the immature cell component of teratomas, which is associated with loss of OCT3/4 expression. Another possibility is that cells expressing OCT3/4 disappear because of apoptosis after NS deletion. Although in one study NS loss induced apoptosis and reduced cell proliferation in ES cells in vitro, ${ }^{22}$ we did not find that NS deficiency led to remarkable induction of apoptosis in teratomas; however, it may be that apoptotic cells were immediately removed by phagocytosis in vivo. Given that we did find remarkable up-regulation of the differentiation marker $\mathrm{TuJ} 1$, cell differentiation induced by NS loss may cause down-regulation of OCT3/4 in mouse teratoma in an indirect manner. Recently, $\mathrm{Qu}$ and Bishop ${ }^{45}$ reported that NS is elevated during reprogramming of somatic cells to pluripotent status and that ectopic NS cooperates with OCT3/4 and SOX-2 for this reprogramming. Although it is unknown how NS is involved in the reprogramming, such mechanisms may underlie the maintenance of the undifferentiated status of germ cell tumors.

Currently, treatment for TGCTs is a cisplatin-based combination chemotherapy. ${ }^{46}$ Although patients with TGCTs benefit from this treatment, novel therapeutic approaches are needed to achieve a cure. To eradicate all tumor cells, it would be important to particularly target the cells that express NS and OCT3/4, because, as we have shown with the present study, NS depletion contributes to the suppression of tumor progression. The investigation of other potent chemical compounds may lead to novel therapeutic approaches for the successful eradication of TGCTs.

\section{Acknowledgments}

We thank Miyako Takegami, Yasuko Tamura, and Kazue Sawa for expert technical support, Dr. Hitoshi Niwa (RIKEN Center for Developmental Biology, Japan) for providing ZHBTcH4 ES cells, and Dr. Junichi Miyazaki (Osaka University Graduate School of Medicine) for providing pCAGGS.

\section{Supplemental Data}

Supplemental material for this article can be found at http://dx.doi.org/10.1016/j.ajpath.2013.04.018.

\section{References}

1. Gilbert D, Rapley E, Shipley J: Testicular germ cell tumours: predisposition genes and the male germ cell niche. Nat Rev Cancer 2011, 11: 278-288

2. Oosterhuis JW, Looijenga LH: Testicular germ-cell tumours in a broader perspective. Nat Rev Cancer 2005, 5:210-222
3. Ginsburg M, Snow MH, McLaren A: Primordial germ cells in the mouse embryo during gastrulation. Development 1990, 110:521-528

4. Tesar PJ, Chenoweth JG, Brook FA, Davies TJ, Evans EP, Mack DL, Gardner RL, McKay RD: New cell lines from mouse epiblast share defining features with human embryonic stem cells. Nature 2007, 448: 196-199

5. Brons IG, Smithers LE, Trotter MW, Rugg-Gunn P, Sun B, Chuva de Sousa Lopes SM, Howlett SK, Clarkson A, Ahrlund-Richter L, Pedersen RA, Vallier L: Derivation of pluripotent epiblast stem cells from mammalian embryos. Nature 2007, 448:191-195

6. Hasthorpe S, Barbic S, Farmer PJ, Hutson JM: Neonatal mouse gonocyte proliferation assayed by an in vitro clonogenic method. J Reprod Fertil 1999, 116:335-344

7. McLaren A: Primordial germ cells in the mouse. Dev Biol 2003, 262: $1-15$

8. Matsui Y: The molecular mechanisms regulating germ cell development and potential. J Androl 2010, 31:61-65

9. Almstrup K, Hoei-Hansen CE, Nielsen JE, Wirkner U, Ansorge W, Skakkebaek NE, Rajpert-De Meyts E, Leffers H: Genome-wide gene expression profiling of testicular carcinoma in situ progression into overt tumours. Br J Cancer 2005, 92:1934-1941

10. Santagata S, Ligon KL, Hornick JL: Embryonic stem cell transcription factor signatures in the diagnosis of primary and metastatic germ cell tumors. Am J Surg Pathol 2007, 31:836-845

11. Gopalan A, Dhall D, Olgac S, Fine SW, Korkola JE, Houldsworth J, Chaganti RS, Bosl GJ, Reuter VE, Tickoo SK: Testicular mixed germ cell tumors: a morphological and immunohistochemical study using stem cell markers, OCT3/4, SOX2 and GDF3, with emphasis on morphologically difficult-to-classify areas. Mod Pathol 2009, 22: 1066-1074

12. Tsai RY, McKay RD: A nucleolar mechanism controlling cell proliferation in stem cells and cancer cells. Genes Dev 2002, 16:2991-3003

13. Meng L, Yasumoto H, Tsai RY: Multiple controls regulate nucleostemin partitioning between nucleolus and nucleoplasm. J Cell Sci 2006, 119:5124-5136

14. Bassler J, Kallas M, Hurt E: The NUG1 GTPase reveals and N-terminal RNA-binding domain that is essential for association with $60 \mathrm{~S}$ pre-ribosomal particles. J Biol Chem 2006, 281:24737-24744

15. Kudron MM, Reinke V: C. elegans nucleostemin is required for larval growth and germline stem cell division. PLoS Genet 2008, 4:e1000181

16. Romanova L, Grand A, Zhang L, Rayner S, Katoku-Kikyo N, Kellner S, Kikyo N: Critical role of nucleostemin in pre-rRNA processing. J Biol Chem 2009, 284:4968-4977

17. Zhu Q, Yasumoto H, Tsai RY: Nucleostemin delays cellular senescence and negatively regulates TRF1 protein stability. Mol Cell Biol 2006, 26:9279-9290

18. Meng L, Hsu JK, Zhu Q, Lin T, Tsai RY: Nucleostemin inhibits TRF1 dimerization and shortens its dynamic association with the telomere. J Cell Sci 2011, 124:3706-3714

19. Hsu JK, Lin T, Tsai RY: Nucleostemin prevents telomere damage by promoting PML-IV recruitment to SUMOylated TRF1. J Cell Biol 2012, 197:613-624

20. Okamoto N, Yasukawa M, Nguyen C, Kasim V, Maida Y, Possemato R, Shibata T, Ligon KL, Fukami K, Hahn WC, Masutomi K: Maintenance of tumor initiating cells of defined genetic composition by nucleostemin. Proc Natl Acad Sci USA 2011, 108: 20388-20393

21. Beekman C, Nichane M, De Clercq S, Maetens M, Floss T, Wurst W, Bellefroid E, Marine JC: Evolutionarily conserved role of nucleostemin: controlling proliferation of stem/progenitor cells during early vertebrate development. Mol Cell Biol 2006, 26:9291-9301

22. Nomura J, Maruyama M, Katano M, Kato H, Zhang J, Masui S, Mizuno Y, Okazaki Y, Nishimoto M, Okuda A: Differential requirement for nucleostemin in embryonic stem cell and neural stem cell viability. Stem Cells 2009, 27:1066-1076

23. Ohmura M, Naka K, Hoshii T, Muraguchi T, Shugo H, Tamase A, Uema N, Ooshio T, Arai F, Takubo K, Nagamatsu G, Hamaguchi I, 
Takagi M, Ishihara M, Sakurada K, Miyaji H, Suda T, Hirao A: Identification of stem cells during prepubertal spermatogenesis via monitoring of nucleostemin promoter activity. Stem Cells 2008, 26:3237-3246

24. Niwa H, Miyazaki J, Smith AG: Quantitative expression of Oct-3/4 defines differentiation, dedifferentiation or self-renewal of ES cells. Nat Genet 2000, 24:372-376

25. Soga T, Ohashi Y, Ueno Y, Naraoka H, Tomita M, Nishioka T: Quantitative metabolome analysis using capillary electrophoresis mass spectrometry. J Proteome Res 2003, 2:488-494

26. Soga T, Baran R, Suematsu M, Ueno Y, Ikeda S, Sakurakawa T, Kakazu Y, Ishikawa T, Robert M, Nishioka T, Tomita M: Differential metabolomics reveals ophthalmic acid as an oxidative stress biomarker indicating hepatic glutathione consumption. J Biol Chem 2006, 281: 16768-16776

27. Gidekel S, Pizov G, Bergman Y, Pikarsky E: Oct-3/4 is a dosedependent oncogenic fate determinant. Cancer Cell 2003, 4:361-370

28. Gaskell TL, Esnal A, Robinson LL, Anderson RA, Saunders PT: Immunohistochemical profiling of germ cells within the human fetal testis: identification of three subpopulations. Biol Reprod 2004, 71:2012-2021

29. Huang M, Whang P, Chodaparambil JV, Pollyea DA, Kusler B, Xu L, Felsher DW, Mitchell BS: Reactive oxygen species regulate nucleostemin oligomerization and protein degradation. J Biol Chem 2011, 286:11035-11046

30. Lo D, Dai MS, Sun XX, Zeng SX, Lu H: Ubiquitin- and MDM2 E3 ligase-independent proteasomal turnover of nucleostemin in response to GTP depletion. J Biol Chem 2012, 287:10013-10020

31. Hirai H, Romanova L, Kellner S, Verma M, Rayner S, Asakura A, Kikyo N: Post-mitotic role of nucleostemin as a promoter of skeletal muscle cell differentiation. Biochem Biophys Res Commun 2010, 391: 299-304

32. Shugo H, Ooshio T, Naito M, Naka K, Hoshii T, Tadokoro Y, Muraguchi T, Tamase A, Uema N, Yamashita T, Nakamoto Y, Suda T, Kaneko S, Hirao A: Nucleostemin in injury-induced liver regeneration. Stem Cells Dev 2012, 21:3044-3054

33. Tamase A, Muraguchi T, Naka K, Tanaka S, Kinoshita M, Hoshii T, Ohmura M, Shugo H, Ooshio T, Nakada M, Sawamoto K, Onodera M, Matsumoto K, Oshima M, Asano M, Saya H, Okano H, Suda T, Hamada J, Hirao A: Identification of tumor-initiating cells in a highly aggressive brain tumor using promoter activity of nucleostemin. Proc Natl Acad Sci USA 2009, 106:17163-17168
34. Lin T, Meng L, Li Y, Tsai RY: Tumor-initiating function of nucleostemin-enriched mammary tumor cells. Cancer Res 2010, 70: 9444-9452

35. Ovitt CE, Schöler HR: The molecular biology of Oct-4 in the early mouse embryo. Mol Hum Reprod 1998, 4:1021-1031

36. Niwa H: Molecular mechanism to maintain stem cell renewal of ES cells. Cell Struct Funct 2001, 26:137-148

37. Stefanovic S, Pucéat M: Oct-3/4: not just a gatekeeper of pluripotency for embryonic stem cell, a cell fate instructor through a gene dosage effect. Cell Cycle 2007, 6:8-10

38. Nishimoto M, Fukushima A, Okuda A, Muramatsu M: The gene for the embryonic stem cell coactivator UTF1 carries a regulatory element which selectively interacts with a complex composed of Oct-3/4 and Sox-2. Mol Cell Biol 1999, 19:5453-5465

39. Boiani M, Schöler HR: Regulatory networks in embryo-derived pluripotent stem cells. Nat Rev Mol Cell Biol 2005, 6:872-884

40. Yuan H, Corbi N, Basilico C, Dailey L: Developmental-specific activity of the FGF-4 enhancer requires the synergistic action of Sox2 and Oct-3. Genes Dev 1995, 9:2635-2645

41. Dailey L, Basilico C: Coevolution of HMG domains and homeodomains and the generation of transcriptional regulation by Sox/POU complexes. J Cell Physiol 2001, 186:315-328

42. Matoba R, Niwa H, Masui S, Ohtsuka S, Carter MG, Sharov AA, Ko MS: Dissecting OCT3/4-regulated gene networks in embryonic stem cells by expression profiling. PLoS One 2006, 1:e26

43. Boyer LA, Lee TI, Cole MF, Johnstone SE, Levine SS, Zucker JP, Guenther MG, Kumar RM, Murray HL, Jenner RG, Gifford DK, Melton DA, Jaenisch R, Young RA: Core transcriptional regulatory circuitry in human embryonic stem cells. Cell 2005, 122:947-956

44. Loh YH, Wu Q, Chew JL, Vega VB, Zhang W, Chen X, Bourque G, George J, Leong B, Liu J, Wong KY, Sung KW, Lee CW, Zhao XD, Chiu KP, Lipovich L, Kuznetsov VA, Robson P, Stanton LW, Wei CL, Ruan Y, Lim B, Ng HH: The Oct4 and Nanog transcription network regulates pluripotency in mouse embryonic stem cells. Nat Genet 2006, 38:431-440

45. Qu J, Bishop JM: Nucleostemin maintains self-renewal of embryonic stem cells and promotes reprogramming of somatic cells to pluripotency. J Cell Biol 2012, 197:731-745

46. Masters JR, Köberle B: Curing metastatic cancer: lessons from testicular germ-cell tumours. Nat Rev Cancer 2003, 3:517-525 